\title{
Contemporary (2019) prevalence of cardiovascular disease in adults with type 2 diabetes in Brazil: the cross-sectional CAPTURE study
}

Sérgio Vencio ${ }^{1,2^{*}} \mathbb{0}$, André Gustavo Daher Vianna ${ }^{3,4}$, Mariana Arruda Camara Ferreira da Silva ${ }^{5}$ and Dalton Bertolim Precoma ${ }^{6}$

\begin{abstract}
Background: Type 2 diabetes (T2D) is a known risk factor for cardiovascular disease (CVD), and CVD is a major cause of mortality in patients with T2D. The CAPTURE study investigated the contemporary (2019) prevalence of established CVD in adults with T2D around the world. We report the findings from Brazil.

Methods: The multinational, non-interventional, cross-sectional CAPTURE study was conducted across 13 countries from five continents. The current manuscript explores data for the CAPTURE study sample in Brazil. Standardized demographic and clinical data were collected from adults with T2D aged $\geq 18$ years attending a single routine healthcare visit in primary or specialized care between December 2018 and September 2019. Data were analyzed descriptively.

Results: Data from 912 adults with T2D were collected in the CAPTURE study in Brazil, with 822 patients from primary care and 90 patients from specialized care. Median (interquartile range [IQR]) patient characteristics were as follows: age 64 years $(57 ; 71)$, diabetes duration 11 years $(6 ; 19)$, glycated hemoglobin $7.7 \%(6.7 ; 9.1)$, and body mass index $29.5 \mathrm{~kg} / \mathrm{m}^{2}$ (26.4; 33.5); 59\% were female. The CVD prevalence and atherosclerotic CVD prevalence in the Brazil sample were $43.9 \%$ (95\% confidence interval [Cl] 40.9; 46.8) and 37.6\% (95\% Cl 34.7; 40.5), respectively. The majority of patients with CVD had atherosclerotic CVD (85.8\%). For the specific CVD subtypes, coronary heart disease prevalence was $27.9 \%(95 \% \mathrm{Cl} 25.2 ; 30.5)$, heart failure was $12.4 \%(95 \% \mathrm{Cl} 10.4 ; 14.4)$, cerebrovascular disease was $8.7 \%(95 \% \mathrm{Cl} 6.8$; 10.5), and carotid artery disease was $3.4 \%(95 \% \mathrm{Cl} 2.3 ; 4.5)$. Glucagon-like peptide-1 receptor agonists and/or sodiumglucose co-transporter-2 inhibitors with proven cardiovascular benefit were prescribed to $15.5 \%$ of patients with CVD, compared with $18.4 \%$ of patients without CVD.
\end{abstract}

Conclusions: CAPTURE was the first multinational, standardized study to provide contemporary data on CVD prevalence in adults with T2D in Brazil, and it demonstrated that almost one in two adults with T2D had established CVD. Except for carotid artery disease, the prevalence of all CVD subtypes in adults with T2D in Brazil appeared higher than the global CAPTURE prevalence.

Trial registration NCT03786406, NCT03811288

\footnotetext{
${ }^{*}$ Correspondence: svencio@gmail.com

${ }^{2}$ ICF, Pharmaceutical Institute of Science, Av. Rio Verde, S/N - Cidade Vera

Cruz, Aparecida de Goiânia, GO 74935-530, Brazil
}

Full list of author information is available at the end of the article

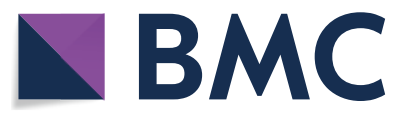

(c) The Author(s) 2022. Open Access This article is licensed under a Creative Commons Attribution 4.0 International License, which permits use, sharing, adaptation, distribution and reproduction in any medium or format, as long as you give appropriate credit to the original author(s) and the source, provide a link to the Creative Commons licence, and indicate if changes were made. The images or other third party material in this article are included in the article's Creative Commons licence, unless indicated otherwise in a credit line to the material. If material is not included in the article's Creative Commons licence and your intended use is not permitted by statutory regulation or exceeds the permitted use, you will need to obtain permission directly from the copyright holder. To view a copy of this licence, visit http://creativecommons.org/licenses/by/4.0/. The Creative Commons Public Domain Dedication waiver (http://creativeco mmons.org/publicdomain/zero/1.0/) applies to the data made available in this article, unless otherwise stated in a credit line to the data. 
Keywords: Atherosclerosis, Brazil, Cardiovascular disease, Cross-sectional study, Prevalence, Type 2 diabetes

\section{Background}

The prevalence of diabetes, and its associated morbidity and mortality, has been increasing globally [1]. Although there is a paucity of contemporary population-based studies on the prevalence of diabetes in Brazil, the trend is also rising [2]. A cross-sectional study of diabetes mellitus with blood testing, conducted between 1986 and 1988 , in a random sample of 21,847 individuals aged 30 to 69 years from nine large Brazilian cities, reported an overall prevalence of 7.6\% [3]. More recently, the International Diabetes Federation (IDF) has estimated a national prevalence of diabetes of $11.4 \%$ among adults aged 20 to 79 years. This represents an estimated 16.8 million people currently living with diabetes, with the figure predicted to rise to 26 million by 2045 . These data have resulted in Brazil's overall ranking of fifth among the top countries with diabetes [1]. In 2014, the Brazilian Longitudinal Study of Adult Health (ELSA) in civil servants aged 35-74 years reported $19.7 \%$ of people with diabetes, out of which $50.4 \%$ were previously undiagnosed [4]. More recent data from the Risk and Protection Factors Surveillance System for Chronic Diseases by Telephone Survey (Vigitel) study in 2019 showed that the prevalence of self-reported diabetes in adults was $7.4 \%$, indicating an increase compared with 2011, which was 5.6\% [5].

Diabetes is a known risk factor for cardiovascular disease (CVD). Results of a cross-sectional study in Brazil estimating the cardiovascular (CV) risk in 1382 patients with type 2 diabetes (T2D) reported that the majority of patients were at a high risk of coronary heart disease (CHD), in particular those patients with chronic microvascular complications, or those who are overweight or obese [6]. In a separate population-based study in Brazil, a higher prevalence of metabolic syndrome was reported in patients with T2D compared with the overall population [2]. Meanwhile, results of a systematic literature review estimating the global prevalence of CVD among adults with T2D over a 10-year period (2007 to 2017) reported that CVD affected $32.2 \%$ of the $4,549,481$ persons with T2D who were included in the analysis [7]. The national prevalence in Brazil was reported to be $27.5 \%$ [7]. The authors also reported that CVD accounted for half of all deaths that occurred globally during the study period [7].

Based on the increasing evidence that CVD is a major cause of mortality in patients with T2D $[2,7,8]$, there has been an escalating emphasis on the management of CVD risk factors in individuals with T2D. Indeed, guidance on the prevention of CVD in patients with diabetes is available from the 2017 position statement from the Brazilian Diabetes Society (SBD), the Brazilian Cardiology Society (SBC), and the Brazilian Endocrinology and Metabolism Society (SBEM). This position statement recommends that in patients with $\mathrm{T} 2 \mathrm{D}$ at very high risk of CVD (as defined by the presence of clinical atherosclerotic disease, with previous $\mathrm{CV}$ events), the addition of a glucose-lowering agent (GLA) with demonstrated $\mathrm{CV}$ benefit, namely a sodium-glucose co-transporter-2 inhibitor (SGLT2i) or glucagon-like peptide-1 (GLP-1) analog, can be useful to reduce CV risk [9]. CV outcome trials (CVOTs) demonstrating superiority in terms of $\mathrm{CV}$ safety have been reported for a number of SGLT2is and GLP-1 receptor agonists (GLP-1 RAs), compared with placebo [10-15].

The CAPTURE study (NCT03786406, NCT03811288) was a non-interventional study using a standardized methodology to assess the prevalence of CVD among adults with T2D in 13 countries across the world [16]. Here, we report the CVD prevalence data for Brazil. Additionally, the CAPTURE Brazil study sample was characterized in terms of demographics, clinical parameters, and use of GLAs and CV medication, with a focus on the use of GLAs with demonstrated CV benefit.

\section{Methods}

\section{Study design}

The study design of CAPTURE, a multinational, noninterventional, cross-sectional study conducted across 13 countries, has previously been described [16]. The current manuscript explores the data for the CAPTURE study sample in Brazil.

The protocol was approved by the ethics committee at each participating trial site and the study was conducted in accordance with the provisions of the Declaration of Helsinki [17], the International Society for Pharmacoepidemiology Good Pharmacoepidemiology Practices [18], and local regulations for clinical research in Brazil. All participants provided written informed consent prior to study participation.

\section{Site selection}

Local medical affairs personnel employed by the sponsor provided information on the management of people with T2D in Brazil, including the types of physicians and practices managing patients with T2D. Information was also obtained from the national coordinating investigator and from literature searches. Sites deemed to be representative of the management of T2D in Brazil were invited to 
participate and to complete a feasibility questionnaire. Sites that accepted the invitation were included in the study.

\section{Participants}

Physicians at participating sites invited consecutive adults attending a single routine healthcare visit in primary or specialized care between December 2018 and September 2019 to participate within a 90-day time period. Eligible participants were aged 18 years and older at the time of informed consent, with a diagnosis of $\mathrm{T} 2 \mathrm{D} \geq 180$ days prior to providing informed consent. Exclusion criteria were a diagnosis of type 1 diabetes, congenital heart disease or malformation, previous participation in this study, mental incapacity, unwillingness, or language barriers precluding an adequate understanding or cooperation.

\section{Data collection}

Data, including demographic, anthropometric and clinical parameters, selected medical history, GLAs, and CV medications, were collected from patients' medical records by physicians or appropriately qualified and trained individuals. Data on medications only included those currently in use or those discontinued within $\leq 3$ months. GLAs were categorized according to $\mathrm{CV}$ benefit, as demonstrated in CVOTs, and based on the 2020 American Diabetes Association guidelines; the GLAs with CV benefit included three GLP-1 RAs (dulaglutide, liraglutide, and semaglutide) and three SGLT2is (canagliflozin, dapagliflozin, and empagliflozin) [19].

\section{Objectives/endpoints of the study}

The primary objective of CAPTURE was to assess CVD prevalence in adults with T2D across 13 countries and individually, including Brazil, using a standardized methodology. This report focuses on the CVD prevalence data from Brazil. Furthermore, the use of CV medications and GLAs with demonstrated CV benefit in Brazil was also assessed. CVD was defined as the presence of any of the following subtypes: cerebrovascular disease, carotid artery disease, CHD, peripheral artery disease (PAD), heart failure, cardiac arrhythmia, or aortic disease. Additionally, atherosclerotic CVD (ASCVD) was designated as a subset of CVD subtypes and included the following diagnoses: cerebrovascular disease, CHD, PAD, or carotid artery disease [20] (Additional file 1: Table S1).

\section{Statistical analysis}

Data for the study sample characteristics (including overall CVD prevalence) for the overall CAPTURE population in Brazil, in addition to subgroups stratified according to the presence of CVD (i.e., CVD and
Non-CVD), were analyzed descriptively only and not statistically due to the study design. Calculated prevalence estimates were weighted by primary care/specialist care setting within Brazil.

\section{Results \\ Study population}

Data from 912 patients with T2D were collected across 21 sites in the CAPTURE study in Brazil, with 822 patients attending primary care sites and 90 attending specialist care sites. Participating trial sites recruited an average of 43.4 patients (range: 6 to 100) (trial sites are listed in Additional file 1: Table S2).

Analysis of the data for key demographic or clinical characteristics of the overall CAPTURE Brazil sample showed that $59.0 \%$ of the population were female; median (interquartile range [IQR]) data for age were 64.0 years (57.0; 71.0), with diabetes duration 11.0 years $(6.0 ; 19.0)$, glycated hemoglobin $\left(\mathrm{HbA}_{1 \mathrm{c}}\right) 7.7 \%$ (6.7; 9.1), and body mass index (BMI) $29.5 \mathrm{~kg} / \mathrm{m}^{2}$ (26.4; 33.5). Hypertension was present in $80.9 \%$ of the overall population and kidney dysfunction (estimated glomerular filtration rate [eGFR] $<59 \mathrm{~mL} / \mathrm{min} / 1.73 \mathrm{~m}^{2}$ ) in $35.4 \%$ (Table 1). The proportion of the overall Brazil sample with obesity was $46.4 \% ; 10.4 \%$ of patients had macroalbuminuria, $15.7 \%$ of patients had retinopathy, $28.5 \%$ of patients had nephropathy, and $16.6 \%$ of patients had neuropathy (Table 1 ).

\section{CVD prevalence}

In the CAPTURE Brazil population, the weighted prevalence (95\% confidence interval [CI]) of CVD was $43.9 \%$ (40.9; 46.8) (Table 2). Similarly, the weighted prevalence of ASCVD in the Brazil sample was $37.6 \%(34.7 ; 40.5)$.

In the Brazil sample, the CVD subtypes with the highest weighted prevalence (95\% CI) were CHD 27.9\% (25.2; $30.5)$, heart failure $12.4 \%(10.4 ; 14.4)$, and cerebrovascular disease $8.7 \%$ (6.8; 10.5; Fig. 1). Within the cerebrovascular disease subtype, the most prevalent diagnosis was ischemic stroke $(6.4 \% ; 4.8,7.9)$.

Furthermore, among the 400 patients with T2D and CVD in Brazil, 343 (85.8\%) had ASCVD. Analyzing the CVD subtypes in this CVD patient group, CHD was the most common subtype $(63.5 \%$ [ $n=254 / 400]$, followed by heart failure $(28.3 \%$ [ $n=113 / 400]$, cerebrovascular disease $(19.8 \%[n=79 / 400])$, and PAD $(19.0 \%[n=76 / 400])$.

\section{Characteristics of the study population stratified by CVD status}

Stratification of the CAPTURE Brazil population by CVD status revealed that the CVD subgroup, compared with the Non-CVD subgroup, was numerically older (67.0 [IQR 61; 72] vs 62.0 [IQR 55; 69] years), had a lower proportion of females (47.5\% vs $68.0 \%$ ), and a higher 
Table 1 Demographic and clinical characteristics of the CAPTURE study population stratified by CVD status in Brazil

\begin{tabular}{|c|c|c|c|c|c|c|}
\hline \multirow[t]{3}{*}{ Characteristic } & \multirow{2}{*}{\multicolumn{2}{|c|}{$\begin{array}{l}\text { Study population } \\
\mathrm{N}=912\end{array}$}} & \multicolumn{4}{|c|}{ By CVD status } \\
\hline & & & \multicolumn{2}{|c|}{$\begin{array}{l}\text { CVD } \\
n=400\end{array}$} & \multicolumn{2}{|c|}{$\begin{array}{l}\text { Non-CVD } \\
n=512\end{array}$} \\
\hline & $\mathrm{n}$ & Data & n & Data & n & Data \\
\hline Female & 912 & $538(59.0)$ & 400 & $190(47.5)$ & 512 & $348(68.0)$ \\
\hline Age, years [IQR] & 912 & $64.0[57.0 ; 71.0]$ & 400 & $67.0[61.0 ; 72.0]$ & 512 & $62.0[55.0 ; 69.0]$ \\
\hline Race & 912 & & 400 & & 512 & \\
\hline White & & $610(66.9)$ & & $275(68.8)$ & & $335(65.4)$ \\
\hline Asian & & $19(2.1)$ & & $12(3.0)$ & & $7(1.4)$ \\
\hline Black or African American & & $114(12.5)$ & & $59(14.8)$ & & $55(10.7)$ \\
\hline Other & & $169(18.5)$ & & $54(13.5)$ & & $115(22.5)$ \\
\hline Diabetes duration, years [IQR] & 912 & $11.0[6.0 ; 19.0]$ & 400 & $13.2[7.2 ; 21.0]$ & 512 & $10.0[5.5 ; 17.0]$ \\
\hline $\mathrm{HbA}_{1 c} \%[\mathrm{IQR}]$ & 776 & $7.7[6.7 ; 9.1]$ & 323 & $7.8[6.8 ; 9.1]$ & 453 & $7.6[6.6 ; 9.1]$ \\
\hline $\mathrm{HbA}_{1 c}, \mathrm{mmol} / \mathrm{mol}[\mathrm{IQR}]$ & 776 & $60.7[49.7 ; 76.0]$ & 323 & $61.8[50.8 ; 76.0]$ & 453 & $59.6[48.6 ; 76.0]$ \\
\hline $\mathrm{HbA}_{1 \mathrm{c}}$ & 776 & & 323 & & 453 & \\
\hline$<7 \%$ & & $250(32.2)$ & & $91(28.2)$ & & $159(35.1)$ \\
\hline $7-9 \%$ & & $318(41.0)$ & & $148(45.8)$ & & $170(37.5)$ \\
\hline$\geq 9 \%$ & & $208(26.8)$ & & $84(26.0)$ & & $124(27.4)$ \\
\hline $\mathrm{FPG}, \mathrm{mmol} / \mathrm{L}[\mathrm{IQR}]$ & 764 & $7.7[6.2 ; 10.1]$ & 310 & $8.0[6.0 ; 10.2]$ & 454 & $7.6[6.2 ; 9.9]$ \\
\hline $\mathrm{BMI}, \mathrm{kg} / \mathrm{m}^{2}[\mathrm{IQR}]$ & 907 & $29.5[26.4 ; 33.5]$ & 400 & $29.8[26.7 ; 33.4]$ & 507 & $29.4[26.2 ; 33.7]$ \\
\hline Obesity & 907 & & 400 & & 507 & \\
\hline Without obesity & & $486(53.6)$ & & $206(51.6)$ & & $280(55.2)$ \\
\hline With obesity & & $421(46.4)$ & & $194(48.8)$ & & $227(44.7)$ \\
\hline Systolic blood pressure, mmHg [IQR] & 912 & $130.0[120.0 ; 147.0]$ & 400 & $130.0[120.0 ; 147.5]$ & 512 & $130.0[120 ; 145.5]$ \\
\hline LDL cholesterol, mmol/L[IQR] & 692 & $2.3[1.8 ; 3.0]$ & 283 & $2.1[1.6 ; 2.7]$ & 409 & $2.5[1.9 ; 3.2]$ \\
\hline HDL cholesterol, mmol/L [IQR] & 731 & $1.1[0.9 ; 1.4]$ & 304 & $1.1[0.9 ; 1.3]$ & 427 & $1.2[1.0 ; 1.5]$ \\
\hline Triglyceride, mmol/L [IQR] & 737 & $1.8[1.2 ; 2.5]$ & 305 & $1.8[1.3 ; 2.6]$ & 432 & $1.8[1.2 ; 2.5]$ \\
\hline $\mathrm{eGFR}, \mathrm{mL} / \mathrm{min} / 1.73 \mathrm{~m}^{2}$ & 674 & & 281 & & 393 & \\
\hline$>89$ & & $166(24.6)$ & & $46(16.4)$ & & $120(30.5)$ \\
\hline$>59-89$ & & $269(39.9)$ & & $110(39.1)$ & & $159(40.5)$ \\
\hline$>29-59$ & & $193(28.6)$ & & $99(35.2)$ & & $94(23.9)$ \\
\hline$\leq 29$ & & $46(6.8)$ & & $26(9.3)$ & & $20(5.1)$ \\
\hline Albuminuria & 412 & & 174 & & 238 & \\
\hline Normal-mildly increased & & $243(59.0)$ & & $88(50.6)$ & & $155(65.1)$ \\
\hline Microalbuminuria & & $126(30.6)$ & & $70(40.2)$ & & $56(23.5)$ \\
\hline Macroalbuminuria & & $43(10.4)$ & & $16(9.2)$ & & $27(11.3)$ \\
\hline Medical history of hypertension, yes & 909 & $735(80.9)$ & 399 & $355(89.0)$ & 510 & $380(74.5)$ \\
\hline Familial hypercholesterolemia, yes & 742 & $118(15.9)$ & 342 & $59(17.3)$ & 400 & $59(14.8)$ \\
\hline Retinopathy & 912 & & 400 & & 512 & \\
\hline Yes & & $143(15.7)$ & & $85(21.3)$ & & $58(11.3)$ \\
\hline Yes (referred by participant) & & $50(5.5)$ & & $26(6.5)$ & & $24(4.7)$ \\
\hline No & & $719(78.8)$ & & $289(72.3)$ & & $430(84.0)$ \\
\hline Nephropathy & 912 & & 400 & & 512 & \\
\hline Yes & & $260(28.5)$ & & $138(34.5)$ & & $122(23.8)$ \\
\hline Yes (referred by participant) & & $25(2.7)$ & & $14(3.5)$ & & $11(2.1)$ \\
\hline No & & $627(68.8)$ & & $248(62.0)$ & & $379(74.0)$ \\
\hline Neuropathy & 912 & & 400 & & 512 & \\
\hline Yes & & $151(16.6)$ & & $75(18.8)$ & & $76(14.8)$ \\
\hline Yes (referred by participant) & & $49(5.4)$ & & $24(6.0)$ & & $25(4.9)$ \\
\hline No & & $712(78.1)$ & & $301(75.3)$ & & $411(80.3)$ \\
\hline
\end{tabular}


Table 1 (continued)

\begin{tabular}{|c|c|c|c|c|c|c|}
\hline \multirow[t]{3}{*}{ Characteristic } & \multirow{2}{*}{\multicolumn{2}{|c|}{$\begin{array}{l}\text { Study population } \\
\mathrm{N}=912\end{array}$}} & \multicolumn{4}{|c|}{ By CVD status } \\
\hline & & & \multicolumn{2}{|c|}{$\begin{array}{l}\text { CVD } \\
n=400\end{array}$} & \multicolumn{2}{|c|}{$\begin{array}{l}\text { Non-CVD } \\
n=512\end{array}$} \\
\hline & $\mathbf{n}$ & Data & $\mathbf{n}$ & Data & n & Data \\
\hline Smoking status & 907 & & 399 & & 508 & \\
\hline Current & & $53(5.8)$ & & $27(6.8)$ & & $26(5.1)$ \\
\hline Previous & & $270(29.8)$ & & $158(39.6)$ & & $112(22.0)$ \\
\hline Never & & $584(64.4)$ & & $214(53.6)$ & & $370(72.8)$ \\
\hline Duration of smoking, ${ }^{\dagger}$ years & 321 & $29.0(0.0 ; 63.0)$ & 184 & $30.0(0.0 ; 63.0)$ & 137 & $20.0(1.0 ; 60.0)$ \\
\hline Physical activity, ${ }^{\ddagger}$ days per week & 839 & & 361 & & 478 & \\
\hline $0-1$ & & $515(61.4)$ & & $251(69.5)$ & & $264(55.2)$ \\
\hline $2-3$ & & $192(22.9)$ & & $58(16.1)$ & & $134(28.0)$ \\
\hline $4-5$ & & $94(11.2)$ & & $38(10.5)$ & & $56(11.7)$ \\
\hline $6-7$ & & $38(4.5)$ & & $14(3.9)$ & & $24(5.0)$ \\
\hline
\end{tabular}

Data are $\mathrm{n}(\%)$ or median [IQR]

BMI: body mass index; CVD: cardiovascular disease; eGFR: estimated glomerular filtration rate; FPG: fasting plasma glucose; HbA 1 : glycated hemoglobin; HDL: highdensity lipoprotein; IQR: interquartile range; LDL: low-density lipoprotein; N: number of patients in the overall Brazil sample; $n$ : number of patients in each subgroup within the Brazil sample

${ }^{\dagger}$ Only applies to participants categorized as current or previous smokers

${ }^{\ddagger}$ Days with $\geq 30$ min of moderate activity

Table 2 Overall prevalence estimates of CVD and its subtypes: adults with T2D in Brazil $(n=912)$

\begin{tabular}{|c|c|c|c|}
\hline CVD diagnosis & Definition of CVD diagnosis & $\begin{array}{l}\text { Number } \\
\text { of } \\
\text { patients }\end{array}$ & Prevalence $[95 \% \mathrm{Cl}](\%)$ \\
\hline CVD & $\begin{array}{l}\text { Cerebrovascular disease; carotid artery disease; CHD; peripheral artery disease; heart } \\
\text { failure; cardiac arrhythmia; aortic disease }\end{array}$ & 400 & $43.9[40.9 ; 46.8]$ \\
\hline Atherosclerotic CVD & Cerebrovascular disease; carotid artery disease; CHD; peripheral artery disease & 343 & $37.6[34.7 ; 40.5]$ \\
\hline $\mathrm{CHD}$ & $\begin{array}{l}\text { Myocardial infarction; stable coronary artery disease; other ischemic heart disease; } \\
\text { past revascularization procedure }\end{array}$ & 254 & $27.9[25.2 ; 30.5]$ \\
\hline Heart failure & Symptomatic or asymptomatic heart failure; hospitalization for heart failure & 113 & $12.4[10.4 ; 14.4]$ \\
\hline Cerebrovascular disease & Ischemic, hemorrhagic or unspecified stroke; transient ischemic attack & 79 & $8.7[6.8 ; 10.5]$ \\
\hline Peripheral artery disease & $\begin{array}{l}\text { Asymptomatic peripheral artery disease (low-ankle branchial index }[<0.90] \text { or pulse } \\
\text { abolition); claudication; limb ischemia; non-traumatic amputation }\end{array}$ & 76 & $8.3[6.6 ; 10.1]$ \\
\hline $\begin{array}{l}\text { Cardiac arrhythmia and } \\
\text { conduction abnormali- } \\
\text { ties }\end{array}$ & $\begin{array}{l}\text { Atrial fibrillation; atrial flutter; supraventricular or ventricular tachycardia; ventricular } \\
\text { fibrillation. bradyarrhythmia: sinus node dysfunction or AV block }\end{array}$ & 46 & $5.1[3.6 ; 6.5]$ \\
\hline Carotid artery disease & - & 31 & $3.4[2.3 ; 4.5]$ \\
\hline Aortic disease & Aortic dissection or aneurysm; thromboembolic aortic disease & 5 & $0.5[0.1 ; 1.0]$ \\
\hline
\end{tabular}

Data are presented according to reducing prevalence in the CAPTURE Brazil sample

AV: atrioventricular; CHD: coronary heart disease; Cl: confidence interval; CVD: cardiovascular disease; T2D: type 2 diabetes

proportion with hypertension $(89.0 \%$ vs $74.5 \%)$ and kidney dysfunction (eGFR $<59 \mathrm{~mL} / \mathrm{min} / 1.73 \mathrm{~m}^{2}: 44.5 \%$ vs $29.0 \%$ ), in addition to a higher proportion of smokers (current/previous: $46.4 \%$ vs $27.1 \%$ ), although differences between the subgroups were not formally tested. Prevalence of microalbuminuria also appeared higher among the CVD versus the Non-CVD subgroup (40.2\% vs $23.5 \%$ ), as were the microvascular complications of retinopathy $(27.8 \%$ vs $16.0 \%)$, nephropathy $(38.0 \%$ vs $25.9 \%$ ), and neuropathy ( $24.8 \%$ vs $19.7 \%$; Table 1 ; not statistically analyzed).

\section{Use of glucose-lowering medication}

In the total CAPTURE Brazil sample, GLAs were used by $98.7 \%$ of patients overall, with use being similar among the CVD and Non-CVD subgroups (98.3\% and 99.0\%, 


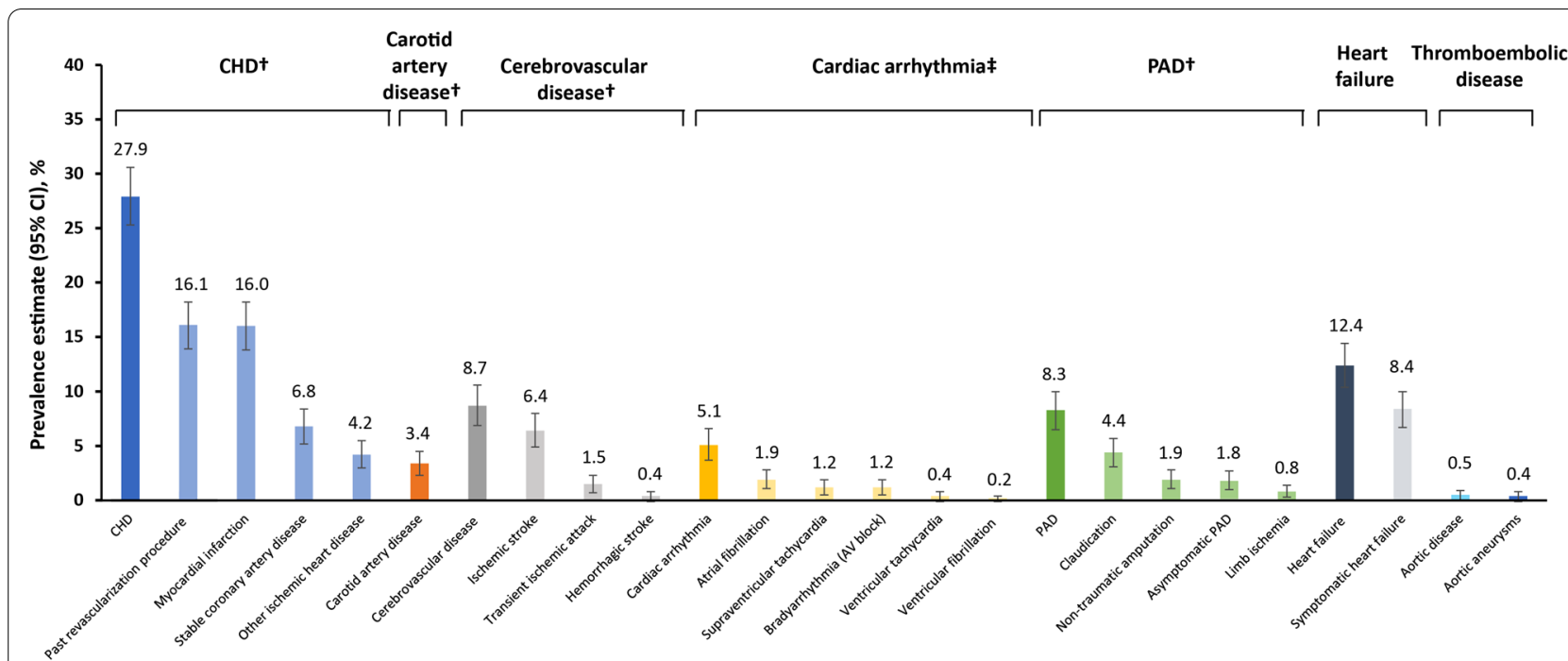

Fig. 1 Prevalence of CVD in Brazil in patients with T2D by CVD subtype and diagnoses. Diagnoses are not mutually exclusive; one participant may have multiple diagnoses. ${ }^{\dagger}$ Categorized as ASCVD. ${ }^{\ddagger}$ Included conduction abnormalities. ASCVD: atherosclerotic CVD; AV: atrioventricular; CHD: coronary heart disease; Cl: confidence interval; CVD: cardiovascular disease; PAD: peripheral artery disease; SND: sinus node dysfunction; T2D: type 2 diabetes

respectively). Oral antidiabetic drugs were used by $88.9 \%$ of the overall population, with a numerically lower proportion of patients in the CVD group receiving oral antidiabetic drugs $(86.0 \%)$ compared with those in the Non-CVD group (91.2\%). Insulin was used by $40.8 \%$ of the overall population, $47.0 \%$ of the CVD population, and $35.9 \%$ of the Non-CVD population (Additional file 1: Table S3). GLAs with proven CV risk reduction-GLP-1 RAs and/or SGLT2is-were prescribed to $17.1 \%$ of the overall population (15.5\% in the CVD subgroup; $18.4 \%$ in the Non-CVD subgroup). SGLT2is were prescribed to $16.0 \%$ of the overall population (14.3\% with CVD; $17.4 \%$ without CVD), while GLP-1 RAs were prescribed to $2.0 \%$ of the overall population (2.8\% with CVD; $1.4 \%$ without CVD; Additional file 1: Fig. S1). Differences between the CVD and Non-CVD subgroups were not formally tested. A summary of the GLP-1 RAs and SGLT2is prescribed to patients in the Brazil sample is provided in Additional file 1: Table S4. Overall, $0.8 \%, 1.0 \%$ and $0.2 \%$ of patients were receiving dulaglutide, liraglutide and semaglutide, respectively, and $11.1 \%$ and $5.0 \%$ of patients were receiving dapagliflozin and empagliflozin, respectively (Additional file 1: Table S4).

\section{Use of $\mathrm{CV}$ medications}

CV medications were used by $89.9 \%$ of the overall Brazil sample, and in $97.8 \%$ and $83.8 \%$ of the CVD and Non-CVD subgroups, respectively. The most frequently prescribed $\mathrm{CV}$ medications in the CVD group were statins (78.5\%), acetylsalicylic acid (54.3\%), and angiotensin II receptor blockers (54.0\%), while the most frequently prescribed $\mathrm{CV}$ medications in the Non-CVD group were statins (56.4\%), angiotensin II receptor blockers $(44.5 \%)$, and thiazides (25.2\%; not statistically analyzed, Additional file 1: Table S5).

\section{Discussion}

CAPTURE represents the first multinational, standardized study to estimate CVD prevalence in adults with T2D. Among the 13 participating countries, Brazil had the highest recruitment, with $9.3 \%(n=912 / 9823)$ of all patients recruited to the CAPTURE study, and the second highest weighted prevalence of CVD (after Israel, which had a prevalence of 50.7\%). Analysis of data for the CAPTURE Brazil sample demonstrated that almost one in two adults (43.9\%) with T2D had established CVD, which is a higher prevalence than that seen in the overall multinational sample (34.8\%) (16).

In Brazil, ASCVD was highly prevalent among patients with T2D (37.6\%; $\mathrm{n}=343 / 912)$ and among those with T2D and CVD (85.8\%; $\mathrm{n}=343 / 400)$. Within the subtypes of CVD, CHD was the most prevalent one, with CHD, heart failure, cerebrovascular disease, and PAD being more prevalent compared with other subtypes (carotid artery disease, cardiac arrhythmia and thromboembolic disease), albeit at lower rates than ASCVD, as ASCVD is a combination of several CVD subtypes. The prevalence of all CVD subtypes were higher in the Brazil sample compared with the multinational sample, with the exception of carotid artery disease, which was lower in the 
Brazil sample than in the multinational sample (3.4\% vs 8.4\%) [16]. It is possible that patients recruited to CAPTURE in Brazil had higher numbers of complications compared with the multinational sample, as the Brazilian centers carrying out research tended to serve complex patients.

Analysis of the sample from Brazil according to CVD status showed that patients in the CVD subgroup compared with the Non-CVD subgroup were older and fewer were female. A higher proportion of the CVD group than the Non-CVD group was also observed to have hypertension, kidney dysfunction, microalbuminuria, and microvascular complications. However, the differences between the CVD subgroups were not formally tested and should, therefore, be interpreted with caution. Hypertensiona common risk factor for CVD [21]-appeared to be more prevalent in the Brazil sample than in the multinational sample $(80.9 \%$ vs $70.1 \%$, respectively), despite the higher use of blood pressure medications in the Brazil sample (use of medications for hypertension and other CVDs: $79.5 \%$ vs $61.4 \%$, respectively [16]). Additionally, kidney dysfunction (eGFR $\left.<59 \mathrm{~mL} / \mathrm{min} / 1.73 \mathrm{~m}^{2}\right)$ was seen in more patients in the Brazil sample (35.4\%) compared with the multinational sample (21.0\%). The median $\mathrm{HbA}_{1 \mathrm{c}}$ levels in Brazil appeared slightly higher versus the multinational sample (7.7\% vs $7.3 \%$, respectively [16]), which would be consistent with the results of a previous study reporting poor glycemic control among Brazilian patients with T2D [22].

It is interesting to note the relatively low use of statins (78.5\%) (and aspirin, 54.3\%) in the CVD group, given the increased emphasis on lipid-lowering (and ongoing prevention of atherosclerotic events) in the 2017 guidelines [9]. Nevertheless, the median LDL levels in the CVD group are within the intermediate risk target $(<2.6 \mathrm{mmol} / \mathrm{L}$ for LDL) stipulated by the guidelines [9] and, compared with the multinational sample (64.2\% for statins and $39.0 \%$ for aspirin) [16], their use is considerably higher.

Use of any GLA with proven CV benefit (GLP-1 RA and/or SGLT2i) was lower in the Brazil sample than in the overall multinational study population $(18.4 \%$ vs $21.9 \%$, respectively [16]). Moreover, the results from the Brazil sample showed that numerically fewer patients in the CVD subgroup, compared with the Non-CVD subgroup, were prescribed any GLAs with proven CV protection or an SGLT2i specifically, while slightly more in the CVD subgroup were prescribed GLP-1 RAs. Potential reasons for the relatively low rate of prescribing GLP-1 RAs, despite their proven CV benefit, might be due to their injectable route of administration, the high cost of these medications and therapeutic inertia [23, 24]. The low rate of prescription of GLAs with proven
$\mathrm{CV}$ benefit may suggest that patients with T2D in Brazil may be managed sub-optimally in this regard. Indeed, in Brazil, a high proportion of patients with diabetes are treated solely in primary care [22], where physicians may not be well-equipped to manage many of these complex patients with established CVD; however, a larger percentage of the CVD group was prescribed antihypertensives compared with the Non-CVD group, indicating that physicians were aware of their increased CV risk and medication need.

There may also have been medication-specific reasons why the rate of the prescription of SGLT2is was lower in the Brazil sample compared with the global sample. For example, in the CAPTURE global sample, a total of 91 patients were treated with the SGLT2i canagliflozin, which has proven CV benefit [25]; however, no patient was treated with canagliflozin in the CAPTURE Brazil sample, possibly due to its label warning (contained within local package inserts/summary of product characteristics/labels) [25-27]. Furthermore, while the 2017 Brazilian guidelines recommend the use of GLP-1 RAs and SGLT-2is to reduce CV risk, some additional key information to support this recommendation was only just presented during/just after the time of data collection $[10,14]$.

Linked to differences in prescribing patterns, a previous sub-analysis of an online survey explored the perceptions and routines of patients with T2D and physicians in Brazil, compared with other countries (USA, UK, Spain, India, and Japan) [28]. Preventing CV events was highlighted as the primary concern of healthcare professionals, while reducing microvascular complications that impacted quality of life was the priority of patients with T2D in Brazil [28]. This discrepancy in priorities between healthcare professionals and patients with T2D in Brazil may lead to poor understanding of the condition and, consequently, a lower use of GLAs with proven $\mathrm{CV}$ benefit in Brazil than in the multinational study sample. Given the relatively low rates of prescription of GLAs with proven $\mathrm{CV}$ benefit in the Brazil sample, education should be delivered to all healthcare professionals in Brazil regarding the CV benefit of SGLT2is and GLP-1 RAs to assist in the prevention of $\mathrm{CV}$ events.

The CAPTURE study in Brazil had a number of limitations. There was the potential for selection bias in this cross-sectional study that may have resulted in study sites and a population sample that were not representative of the management of T2D in Brazil, and the sample size of patients with T2D in secondary care setting is small. Relative to the size of the T2D population in Brazil, the CAPTURE study sample was small $(\mathrm{n}=912$ patients). Data were not formally tested statistically, limiting the robustness of any comparisons. Finally, this 
non-interventional study did not screen or adjudicate for the presence of $\mathrm{CV}$ complications; thus, there may have been under-or over-diagnosis of CVD.

\section{Conclusions}

The CAPTURE study provides valuable contemporary cross-sectional data on CVD prevalence in Brazilian patients with T2D, demonstrating that almost one in two have established CVD, of which the majority have ASCVD. All CVD subtypes had higher prevalence in the Brazil sample compared with the multinational sample, with the exception of carotid artery disease. Standard therapeutic strategies to ameliorate CV risk factors appear to be utilized in this population (i.e. statin and aspirin treatment), although these rates could be improved. Likewise, improvements in $\mathrm{HbA}_{1 \mathrm{c}}$ levels should be strived for. The results also show a lower use of GLAs with demonstrated CV benefits in the Brazil sample versus the multinational sample, despite national guidelines advocating their use in patients with T2D and ASCVD or at very high risk of CVD [9]. Providing more education to healthcare professionals to increase the discussion about the treatment of patients with T2D and CVD could help to reduce clinical inertia and improve patient outcomes.

\begin{abstract}
Abbreviations
ASCVD: Atherosclerotic cardiovascular disease; BMI: Body mass index; CHD: Coronary heart disease; Cl: Confidence interval; CV: Cardiovascular; CVD: Cardiovascular disease; CVOTs: Cardiovascular outcome trials; eGFR: Estimated glomerular filtration rate; GLA: Glucose-lowering agent; GLP-1 RAs: Glucagonlike peptide-1 receptor agonists; GLP-1: Glucagon-like peptide-1; $\mathrm{HbA}_{1}$ : Glycated hemoglobin; IDF: International Diabetes Federation; PAD: Peripheral artery disease; SBC: Brazilian Cardiology Society; SBD: Brazilian Diabetes Society; SBEM: Brazilian Endocrinology and Metabolism Society; SGLT2i: Sodiumglucose co-transporter-2 inhibitor; T2D: Type 2 diabetes.
\end{abstract}

\section{Supplementary Information}

The online version contains supplementary material available at https://doi. org/10.1186/s13098-021-00775-9.

Additional file 1: Table S1. Definition of CVD diagnoses in the CAPTURE study. Table S2. List of participating trial sites. Table S3. Use of glucoselowering agents in the CAPTURE study population stratified by CVD status in Brazil. Table S4. Proportion of patients receiving GLP-1 RAs and SGLT2is with proven CV benefit (Brazil). Table S5. Use of CV medications in the CAPTURE study population stratified by CVD status in Brazil. Figure $\mathbf{S} 1$. GLAs with proven CV benefit use in the CAPTURE Brazil sample stratified by CVD status.

\section{Acknowledgements}

The authors would like to thank the CAPTURE study participants, investigators, and coordinators. Medical writing and editing support for the development of this manuscript, under the direction of the authors, was provided by Gillian Groeger, PhD, and Izabel James, MBBS, of Ashfield MedComms, an Ashfield Health company, and funded by Novo Nordisk A/S.

\section{Authors' contributions}

SV is the guarantor of this work and, as such, had full access to all of the data in the study, and takes responsibility for the integrity of the data and the accuracy of the data analysis. All authors confirm that they meet the International Committee of Medical Journal Editors (ICMJE) uniform requirements for authorship and that they have contributed to critical analysis and interpretation of the data, drafting and/or critically revising the article and sharing in the final responsibility for the content of the manuscript, as well as the decision to submit it for publication. All authors read and approved the final manuscript.

\section{Funding}

The funding source (Novo Nordisk A/S) of the CAPTURE study participated in the study design, site selection (in collaboration with a contract research organization), study coordination, data management, data analysis, and study report preparation. This country-level analysis of the CAPTURE data was also funded by Novo Nordisk A/S.

\section{Availability of data and materials}

The datasets supporting the conclusions of this article are included within the article and its additional file. The patient level analysis data sets for the research presented in the article are available from the corresponding author on reasonable request.

\section{Declarations}

\section{Ethics approval and consent to participate}

The protocol was approved by the ethics committee at each participating trial site and the study was conducted in accordance with the provisions of the Declaration of Helsinki [17], the International Society for Pharmacoepidemiology Good Pharmacoepidemiology Practices [12], and local regulations for clinical research in Brazil. All participants provided written informed consent prior to study participation.

\section{Consent for publication}

Not applicable.

\section{Competing interests}

SV-Research grants: Novo Nordisk, Biomm, Bayer and Cristalia; honoraria for consultancy or giving lectures: AstraZeneca, Novo Nordisk, Boehringer Ingelheim, and Novartis; he is also the Editor-in-Chief of Diabetology \& Metabolic Syndrome and this article was independently handled by the Deputy Editorin-Chief. AV_-Advisory Board: Novo Nordisk, Sanofi, Biomm, Abbott Diabetes Care, and Medtronic; speaker: Novo Nordisk, Sanofi, Biomm, Abbott Diabetes Care, Servier, MSD, Medtronic, Lilly, and AstraZeneca; research Grants: Novo Nordisk, AstraZeneca, and Lilly. MS-Employee of and shareholder in Novo Nordisk. DP_-Research grants: Novo Nordisk, Bayer, Boehringer Ingelheim, Novartis, Daiichi-Sankyo, Amgen, Vifor-Pharma, and AstraZeneca; advisory board: Servier and Bayer.

\section{Author details}

${ }^{1}$ UFG - Federal University of Goiás, Goiânia, GO, Brazil. ${ }^{2}$ ICF, Pharmaceutical Institute of Science, Av. Rio Verde, S/N - Cidade Vera Cruz, Aparecida de Goiânia, GO 74935-530, Brazil. ${ }^{3}$ Curitiba Diabetes Center, Curitiba, PR, Brazil. ${ }^{4}$ Nossa Senhora das Graças Hospital, Curitiba, PR, Brazil. ${ }^{5}$ Novo Nordisk, São Paulo, SP, Brazil. ${ }^{6}$ Research Center at Angelina Caron Hospital, Campina Grande do Sul, PR, Brazil.

Received: 30 July 2021 Accepted: 23 December 2021

Published online: 10 January 2022

\section{References}

1. International Diabetes Federation. IDF Diabetes Atlas. 9th ed. Brussels, Belgium2019. https://www.diabetesatlas.org/en/.

2. do Vale Moreira NC, Hussain A, Bhowmik B, Mdala I, Siddiquee T, Fernandes VO, et al. Prevalence of metabolic syndrome by different definitions, and its association with type 2 diabetes, pre-diabetes, and cardiovascular disease risk in Brazil. Diabetes Metab Syndr. 2020;14:1217-24. 
3. Malerbi DA, Franco LJ. Multicenter study of the prevalence of diabetes mellitus and impaired glucose tolerance in the urban Brazilian population aged 30-69 yr. The Brazilian Cooperative Group on the Study of Diabetes Prevalence. Diabetes Care. 1992;15:1509-16.

4. Schmidt MI, Hoffmann JF, de Fátima Sander Diniz M, Lotufo PA, Griep RH, Bensenor IM, et al. High prevalence of diabetes and intermediate hyperglycemia-The Brazilian Longitudinal Study of Adult Health (ELSA-Brasil). Diabetol Metab Syndr. 2014;6:123.

5. (BR) MdS. Vigitel Brasil 2019: vigilância de fatores de risco e proteção para doenças crônicas por inquérito telefônico: estimativas sobre frequência e distribuição sociodemográfica de fatores de risco e proteção para doenças crônicas nas capitais dos 26 estados brasileiros e no Distrito Federal em 2019. Brasília, DF: MSi; Disponível em: https://portalarquivos.saude. gov.br/images/pdf/2020/April/27/vigitel-brasil-2019-vigilancia-fatoresrisco.pdf. 2020

6. Gomes MB, Giannella-Neto D, Faria M, Tambascia M, Fonseca RM, Rea R, et al. Estimating cardiovascular risk in patients with type 2 diabetes: a national multicenter study in Brazil. Diabetol Metab Syndr. 2009;1:22.

7. Einarson TR, Acs A, Ludwig C, Panton UH. Prevalence of cardiovascular disease in type 2 diabetes: a systematic literature review of scientific evidence from across the world in 2007-2017. Cardiovasc Diabetol. 2018;17:83.

8. Abdul-Ghani M, DeFronzo RA, Del Prato S, Chilton R, Singh R, Ryder REJ. Cardiovascular disease and type 2 diabetes: has the dawn of a new era arrived? Diabetes Care. 2017:40:813-20.

9. Bertoluci MC, Moreira RO, Faludi A, Izar MC, Schaan BD, Valerio CM, et al. Brazilian guidelines on prevention of cardiovascular disease in patients with diabetes: a position statement from the Brazilian Diabetes Society (SBD), the Brazilian Cardiology Society (SBC) and the Brazilian Endocrinology and Metabolism Society (SBEM). Diabetol Metab Syndr. 2017;9:53.

10. Gerstein HC, Colhoun HM, Dagenais GR, Diaz R, Lakshmanan M, Pais $P$, et al. Dulaglutide and cardiovascular outcomes in type 2 diabetes (REWIND): a double-blind, randomised placebo-controlled trial. Lancet. 2019;394:121-30

11. Marso SP, Daniels GH, Brown-Frandsen K, Kristensen P, Mann JF, Nauck MA, et al. Liraglutide and cardiovascular outcomes in type 2 diabetes. $\mathrm{N}$ Engl J Med. 2016;375:311-22.

12. Marso SP, Bain SC, Consoli A, Eliaschewitz FG, Jódar E, Leiter LA, et al. Semaglutide and cardiovascular outcomes in patients with type 2 diabetes. N Engl J Med. 2016;375:1834-44.

13. Mahaffey KW, Neal B, Perkovic V, de Zeeuw D, Fulcher G, Erondu N, et al. Canagliflozin for primary and secondary prevention of cardiovascular events: results from the CANVAS Program (Canagliflozin Cardiovascular Assessment Study). Circulation. 2018;137:323-34.

14. Wiviott SD, Raz I, Bonaca MP, Mosenzon O, Kato ET, Cahn A, et al. Dapagliflozin and cardiovascular outcomes in type 2 diabetes. N Engl J Med. 2018:380:347-57.

15. Zinman B, Wanner C, Lachin JM, Fitchett D, Bluhmki E, Hantel S, et al. Empagliflozin, cardiovascular outcomes, and mortality in type 2 diabetes. N Engl J Med. 2015;373:2117-28.

16. Mosenzon O, Alguwaihes A, Leon JLA, Bayram F, Darmon P, Davis TME, et al. CAPTURE: a multinational, cross-sectional study of cardiovascular disease prevalence in adults with type 2 diabetes across 13 countries. Cardiovasc Diabetol. 2021;20(1):154.

17. World Medical Association. Declaration of Helsinki: ethical principles for medical research involving human subjects. JAMA. 2013;310:2191-4.

18. International Society for Pharmacoepidemiology (ISPE). Guidelines for Good Pharmacoepidemiology Practices (GPP). 2015 https://www.pharm acoepi.org/resources/policies/guidelines-08027/. Accessed Sep 2020.

19. American Diabetes Association. 10. Cardiovascular disease and risk management: standards of medical care in diabetes. Diabetes Care. 2020:43:S111-s34.

20. Arnett DK, Blumenthal RS, Albert MA, Buroker AB, Goldberger ZD, Hahn EJ, et al. ACC/AHA Guideline on the primary prevention of cardiovascular disease: executive summary: a report of the American College of Cardiology/American Heart Association Task Force on Clinical Practice Guidelines. J Am Coll Cardiol. 2019;2019(141):1376-414

21. Martín-Timón I, Sevillano-Collantes C, Segura-Galindo A, Del CañizoGómez FJ. Type 2 diabetes and cardiovascular disease: have all risk factors the same strength? World J Diabetes. 2014;5:444-70.
22. de Almeida-Pititto B, Dias ML, de Moraes AC, Ferreira SR, Franco DR, Eliaschewitz FG. Type 2 diabetes in Brazil: epidemiology and management. Diabetes Metab Syndr Obes. 2015;8:17-28.

23. American Diabetes Association. 9. Pharmacologic approaches to glycemic treatment: standards of medical care in diabetes-2021. Diabetes Care. 2021;44:S111-s24.

24. Kanumilli N, Brunton S, Cos X, Deed G, Kushner P, Lin P, et al. Global survey investigating causes of treatment inertia in type 2 diabetes cardiorenal risk management. J Diabetes Complicat. 2021:35:107813.

25. INVOKANA (canagliflozin) [package insert]. Titusville, NJ: Janssen Pharmaceuticals, Inc. https://www.janssenlabels.com/package-insert/produ ct-monograph/prescribing-information/INVOKANA-pi.pdf. Accessed 20 Nov 2021.

26. INVOKANA (canagliflozin) [summary of product characteristics]. Titusville, NJ: Janssen Pharmaceuticals, Inc. . https://www.ema.europa.eu/en/ documents/product-information/invokana-epar-product-information_ en.pdf. Accessed 20 Nov 2021

27. IDENTIFICAÇÃO DO MEDICAMENTO (Identification of medicinal product): JANSSEN-CILAG FARMACÊUTICA LTDA. (Sao Paulo, Brasil). https://www. janssen.com/brasil/sites/www_janssen_com_brazil/files/prod_files/live/ invokana_pub_vps.pdf Accessed 2 Mar 2021.

28. Vencio S, Paldánius PM, Blüher M, Giannella-Neto D, Caiado-Vencio R, Strain WD. Understanding the barriers and improving care in type 2 diabetes: Brazilian perspective in time to do more in diabetes. Diabetol Metab Syndr. 2017;9:46. https://doi.org/10.1186/s13098-017-0244-y.

\section{Publisher's Note}

Springer Nature remains neutral with regard to jurisdictional claims in published maps and institutional affiliations.
Ready to submit your research? Choose BMC and benefit from:

- fast, convenient online submission

- thorough peer review by experienced researchers in your field

- rapid publication on acceptance

- support for research data, including large and complex data types

- gold Open Access which fosters wider collaboration and increased citations

- maximum visibility for your research: over $100 \mathrm{M}$ website views per year

At BMC, research is always in progress.

Learn more biomedcentral.com/submissions 